\title{
Biotrickling filtration of $n$-butanol vapors: process monitoring using electronic nose and artificial neural network
}

\author{
Bartosz Szulczyński ${ }^{1}$ [D $\cdot$ Piotr Rybarczyk ${ }^{1} \cdot$ Milena Gospodarek $^{1} \cdot$ Jacek Gębicki $^{1}$
}

Received: 28 February 2019 / Revised: 25 May 2019 / Accepted: 12 June 2019 / Published online: 13 August 2019

(c) The Author(s) 2019

\begin{abstract}
Biotrickling filtration is one of the techniques used to reduce odorants in the air. It is based on the aerobic degradation of pollutants by microorganisms located in the filter bed. The research presents the possibility of using the electronic nose prototype combined with artificial neural network for biofiltration process monitoring in terms of reduction in $n$-butanol concentration and odour intensity of treated air. The study was conducted using two-section biotrickling filter packed with a commercially available mixture of peat and perlite during 42 days with different $n$-butanol inlet concentrations, i.e., 100, 200, 400, and $800 \mathrm{ppm}$. During the tests, a concentration and odour intensity removal efficiency of around $90 \%$ and $20 \%$ was obtained, respectively. It has been shown that the highest values were obtained for an inlet $n$-butanol concentration of $200-400 \mathrm{ppm}$.
\end{abstract}

Graphic abstract

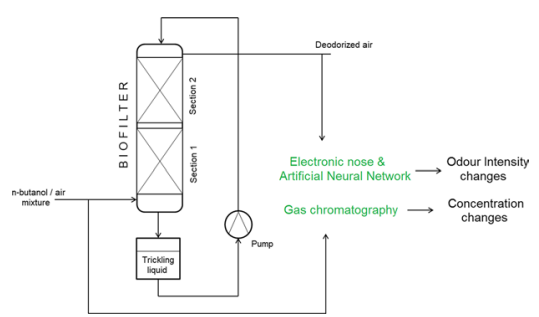

Keywords Neural network $\cdot$ Sensors $\cdot$ Odoriferous substances $\cdot$ Alcohols

\section{Introduction}

Removal of odorous compounds from air, including nitrogen and sulfur compounds as well as volatile organic compounds, is gaining importance due to social awareness and increasingly stringent environmental legislations $[1,2]$. Such a trend enforces the development of sustainable and efficient methods of air deodorization. Among them, biological methods of gas treatment are considered to be more effective and economical alternative to conventional methods such as

Bartosz Szulczyński

bartosz.szulczynski@pg.edu.pl

1 Department of Process Engineering and Chemical Technology, Faculty of Chemistry, Gdańsk University of Technology, Gdańsk, Poland chemical scrubbing, incineration, absorption, or condensation $[3,4]$. This is especially true when large volumes of gases containing low or medium concentrations of pollutants are taken into account.

One of the most common techniques of biological gas treatment is biofiltration. The process of biofiltration consists in passing a polluted stream of gas through a filter bed, inhabited by microorganisms of various species (typically bacteria or fungi) [5]. The pollutants diffuse from the gas phase to the so-called biofilm, formed on the surface of the elements of the filter packing. The compounds adsorbed on the surface or absorbed in the biofilm undergo biodegradation and the air leaves the biofilter cleansed and free of unpleasant odors. The biofiltration process can be carried out in two main types of apparatus, i.e., in a conventional biofilter or in a biotrickling filter. In a conventional biofilter, the contaminated gas is initially humidified in a separate 
chamber, and only then, it is transferred to the biofilter. The packing of such a biofilter is most often made of natural organic materials, e.g., bark, cones, or peat. The construction of a biotrickling filter, on the other hand, enables the process to be carried out in one apparatus. The filter bed, made of natural or synthetic materials, is regularly trickled with liquid enriched with minerals necessary for the growth of microorganisms. The trickling liquid may circulate in a closed system subject to periodic regeneration. Biotrickling filters allow easier control and regulation of the process, including increased process stability, $\mathrm{pH}$ and temperature control as well as continuous nutrient supply, compared to conventional biofilters [6-8].

Biotrickling filtration is currently considered as the most promising technology of biological air treatment [9]. This results, among others, from the application of mobile liquid phase, providing means for washing out from the bed the biodegradation intermediates, possibly inhibiting the microbial activity in conventional biofilters as well as outstanding process efficiency and economy, as compared to other types of bioreactors [10-12].

In this paper, a counter-current biotrickling filtration of variable inlet loads of $n$-butanol was investigated. Butanol is a representative of hydrophilic volatile organic compound. However, it is treated in biological systems with rather high purification efficiency, and its removal from air in biotrickling filters has been scarcely investigated [13]. In addition, in this study, a biotrickling filter was packed with a mixture of inert and organic materials, i.e., a mixture of perlite and peat, contrary to majority of experimental studies, where biotrickling filters are packed with inert materials (ceramic elements, polyurethane foam, or lava rock) [14]. Such an approach allows a rapid start-up of the process and eliminates the step of inoculating the packing materials with microbial species.

The most frequently used techniques to evaluate effectiveness of biofiltration process are gas chromatography techniques. They enable separation and determination of concentrations of individual components of the mixture. In terms of the evaluation of the odour quality of purification, such information is not directly useful. Therefore, electronic noses-devices enabling holistic analysis of gas samplesare increasingly used to assess the effectiveness of biofiltration $[15,16]$. The electronic nose system consists of four main components, as presented in Fig. 1.

As pattern recognition system various chemometric algorithms are used, e.g., principal component analysis (PCA), linear discriminant analysis (LDA), support vector machine (SVM), or partial least square (PLS). However, the most valuable method used in the e-nose system in artificial neural network (ANN). Artificial neural networks are now considered the best method of analyzing data from artificial senses, mainly due to the fact that ANNs in their architecture and functioning resemble the nervous system in humans. The simplest, having only one neuron, ANN is called the perceptron. The McCulloch-Pitts neuron, which is a simplified model of the biological nerve cell. The similarity in the construction of both neurons is presented in Fig. 2 .

The use of ANN for data analysis is possible only after prior collection of the training data set-examples of inputs along with defined, corresponding output values. Neural network learning process involves changing its internal parameters (weight coefficients and neuron activation thresholds). This is done using the appropriate algorithm, usually learning under supervision. The most frequently used algorithm for this purpose is the back error propagation algorithm
Fig. 1 Electronic nose system description

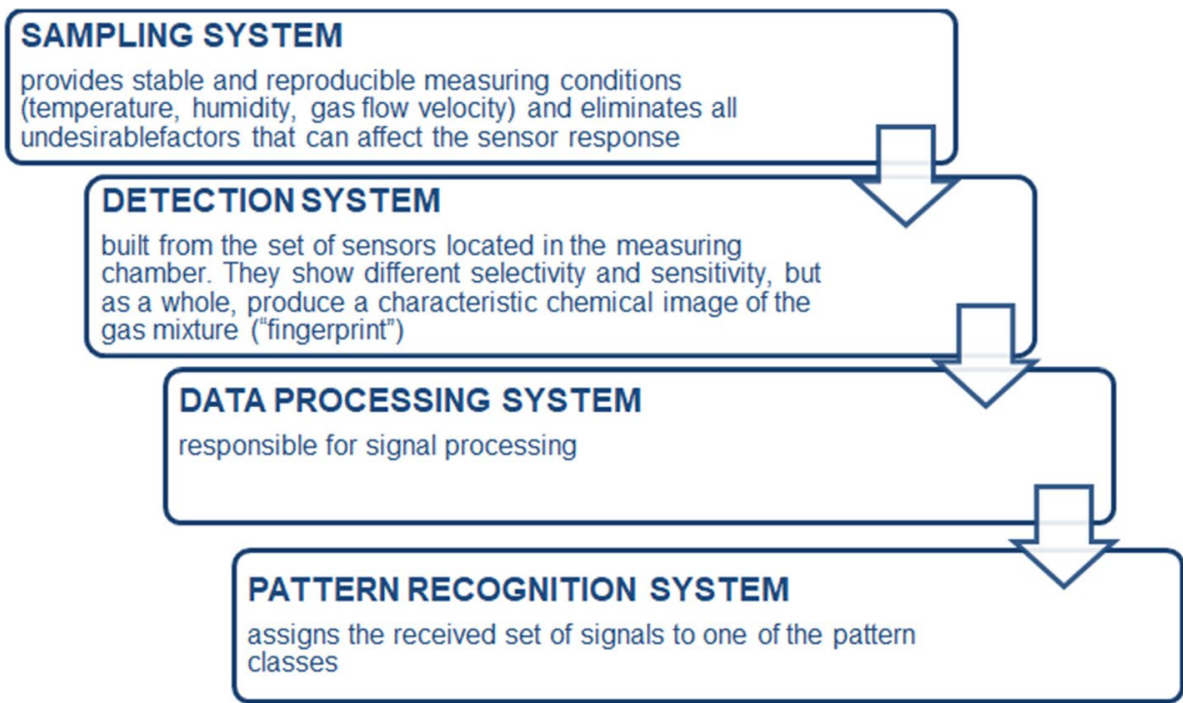


Fig. 2 Similarity of neuron cell and artificial neural network construction

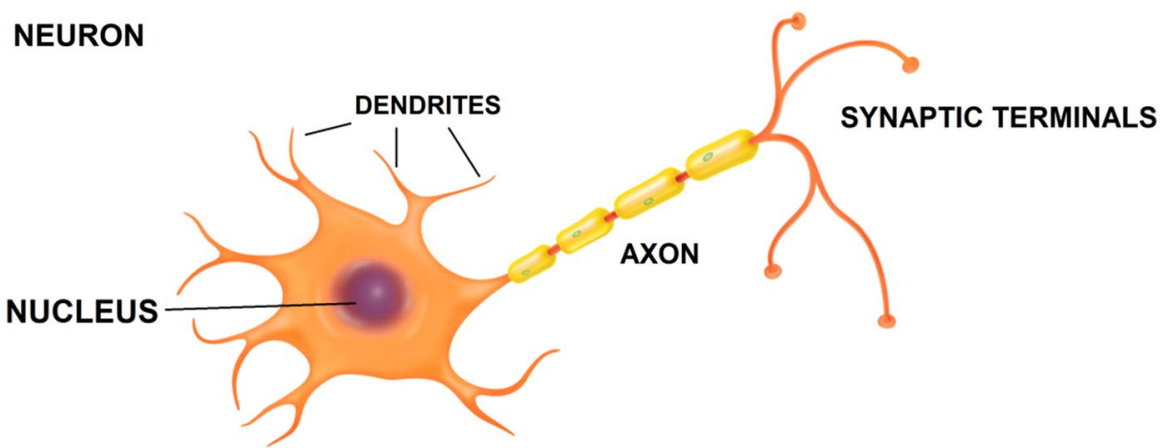

ARTIFICIAL NEURAL NETWORK

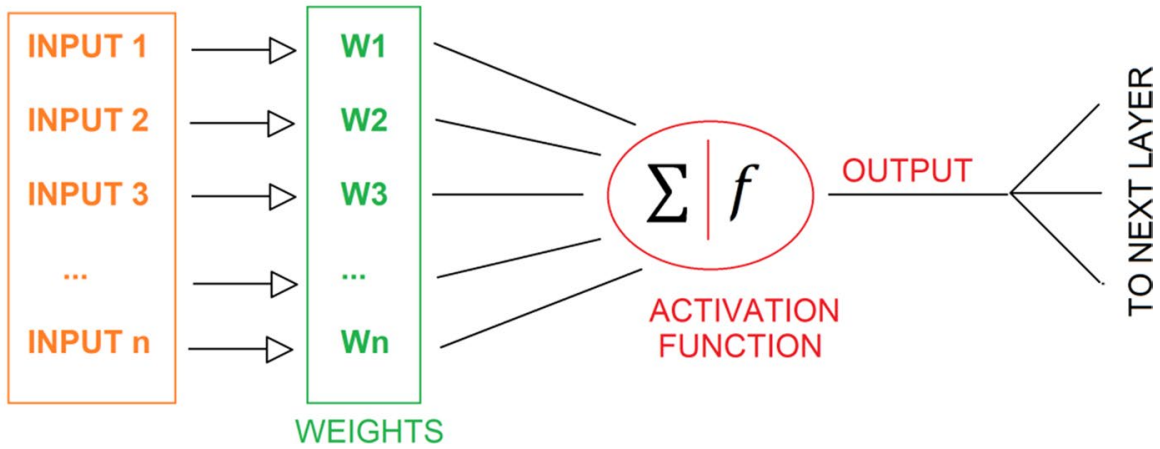

Fig. 3 Concentration removal efficiency $\left(\mathrm{RE}_{\text {conc }}\right)$ changes during the process

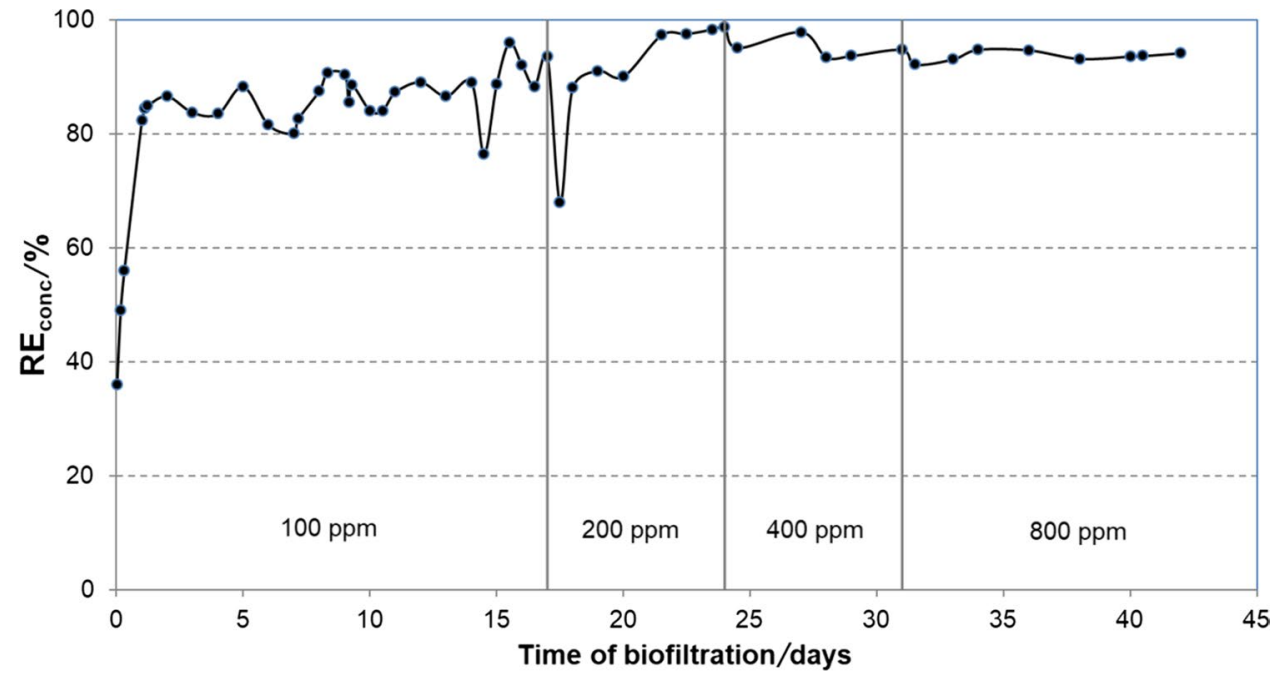

[17]. Its operation consists in the modification of weights and threshold values based on training data in such a way as to minimize the error made by the network while performing its assigned tasks for all data included in the training set.

The article presents estimation of the odour intensity of air samples (contaminated with $n$-butanol) undergoing biofiltration process using electronic nose prototype and artificial neural network. The removal efficiency calculated using odour intensity changes was compared with values calculated using changes in $n$-butanol concentration.

\section{Results and discussion}

The performance of a peat-perlite-packed biotrickling filter is shown in Fig. 3 (concentration changes) and Fig. 4 (odour intensity changes).

Shortly after introducing the mixture of air and $n$-butanol to the biofilter, concentration removal efficiency of about $37 \%$ is obtained and it increases to about $80-85 \%$ during the first day of the process. When continuing the process, values of $\mathrm{RE}_{\text {conc }}$ slightly increase, reaching the values close to $90 \%$ within first 15 days of biofiltration. 
Fig. 4 Odour intensity removal efficiency $\left(\mathrm{RE}_{\mathrm{OI}}\right)$ changes during the process

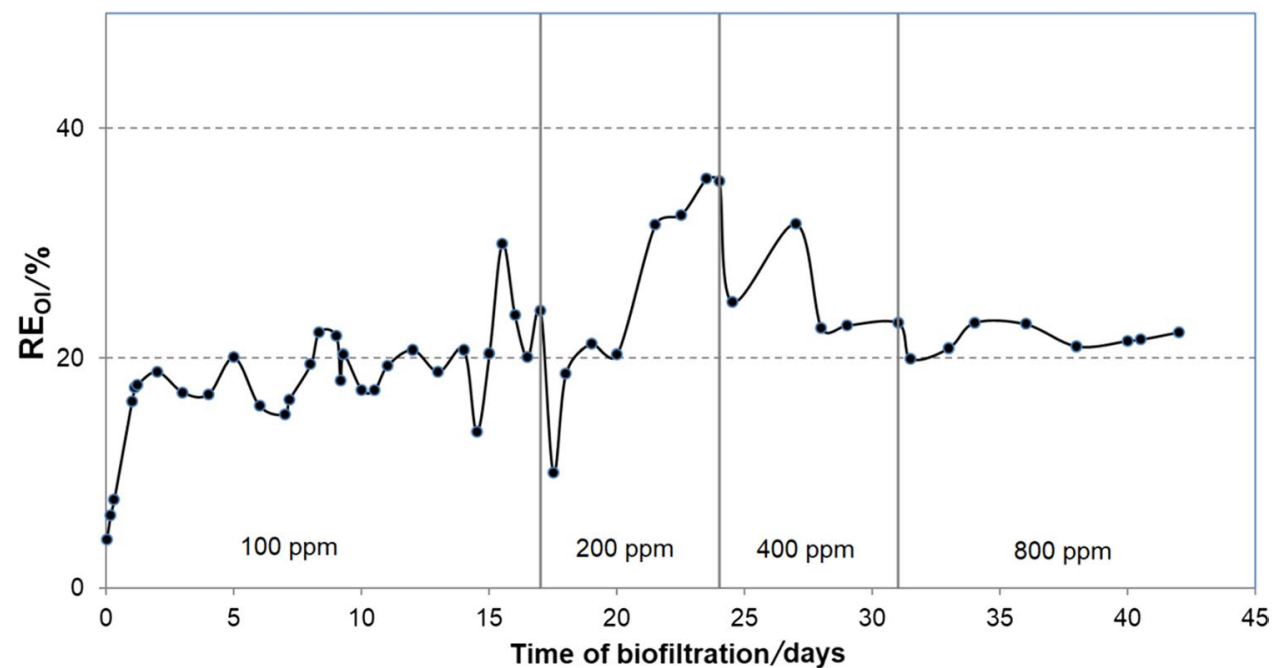

In terms of odour intensity for 0-15 and 31-42 days, removal efficiency was close to $20 \%$. The higher values were noticed for inlet concentrations equal to 200 and $400 \mathrm{ppm}$. Such high values of RE result from two main reasons: first, $n$-butanol is a hydrophilic volatile organic compound and it is easily removed from air streams in biological systems [15, 18]; second, the applied packing of a biotrickling filter is rich in plenty of microbial species which favors biodegradation of air pollutants $[19,20]$. In addition, stable values of $n$-butanol removal efficiency indicate that the biological system attains adaptation to the treated gas and microorganisms present in the peat structure consume $n$-butanol as a source of carbon. Thus, the period of 15 days was assumed as a start-up period, i.e., the time period ensuring steady-state conditions in the system [3].

To investigate the influence of an inlet loading on the efficiency of biofiltration, inlet concentrations of $n$-butanol were increased at 17 th, 24 th, and 31 st days of the process duration. This is reflected by a drop in the RE values corresponding to day 17 th of biofiltration. However, within next 2 days, the concentration removal efficiency increases, reaching the values in the range 95-99\%. Interestingly, further increases in the inlet loading of $n$-butanol (days 24 and 31 ) only slightly influence the values of $\mathrm{RE}_{\text {conc }}$. Such behavior of the system suggests a good adaptation of the microbial species inhabiting the biofilter packing for the treated compound and suggests a stable working conditions for longterm experiments. Obtained results are in accordance with literature data regarding biotrickling filtration of $n$-butanol [21]. It is worth noting that no problems with bed clogging were faced during the investigated period of biofiltration for the set values of EBRT and trickling liquid velocity and frequency (Table 1). The measured pressure drop across the filter packing during the experiment was in the range of about 60-90 $\mathrm{mm} \mathrm{H}_{2} \mathrm{O}$.
Table 1 Basic process parameters of a biotrickling filter

\begin{tabular}{ll}
\hline Parameter & Value \\
\hline Internal diameter of a biofilter & $8 \mathrm{~cm}$ \\
Total height of a two-section biofilter & $68 \mathrm{~cm}$ \\
Total volume of biofilter packing & $2.5 \mathrm{dm}^{3}$ \\
Volumetric flow rate of gas phase & $2.5 \mathrm{dm}^{3} \mathrm{~min}^{-1}$ \\
Empty bed residence time (EBRT) & $60 \mathrm{~s}$ \\
Inlet $n$-butanol concentrations & $100,200,400,800 \mathrm{ppm}$ \\
Height of a Raschig rings layer & \\
$10 \times 2.4$ mm & $3 \mathrm{~cm}$ \\
$6 \times 1.5 \mathrm{~mm}$ & $2 \mathrm{~cm}$ \\
Volumetric flow rate of trickling liquid & $0.2 \mathrm{dm}^{3} \mathrm{~min}^{-1}$ \\
Frequency of trickling & $1 \mathrm{~min}^{-1} \mathrm{~h}^{-1}$ \\
\hline
\end{tabular}

\section{Conclusion}

As a result of the studies, it was found that the electronic nose prototype along with the proposed artificial neural network can be successfully used to estimate the odour intensity of $n$-butanol contaminated air samples undergoing biofiltration process. Presented results indicate that $n$-butanol vapors may be effectively eliminated from air in a biotrickling filter packed with a mixture of peat and perlite. Concentration removal efficiency of $n$-butanol exceeding $90 \%$ has been achieved after the period of 20 days of biofiltration. Such $\mathrm{RE}_{\text {conc }}$ values correspond $20-30 \%$ in odour intensity removal. On 23th day of process duration the highest efficiency was observed $\left(\mathrm{RE}_{\mathrm{conc}}=98.6 \%, \mathrm{RE}_{\mathrm{OI}}=35.4 \%\right)$. High values of RE were observed for inlet concentrations equal to 200 and $400 \mathrm{ppm}$. This allows to conclude that for this biofilter the values of these concentrations are optimal.

The choice of $n$-butanol as the target compound is also justified by previous research, dealing with conventional 
Fig. 5 Schematic diagram of the biotrickling filter experimental setup

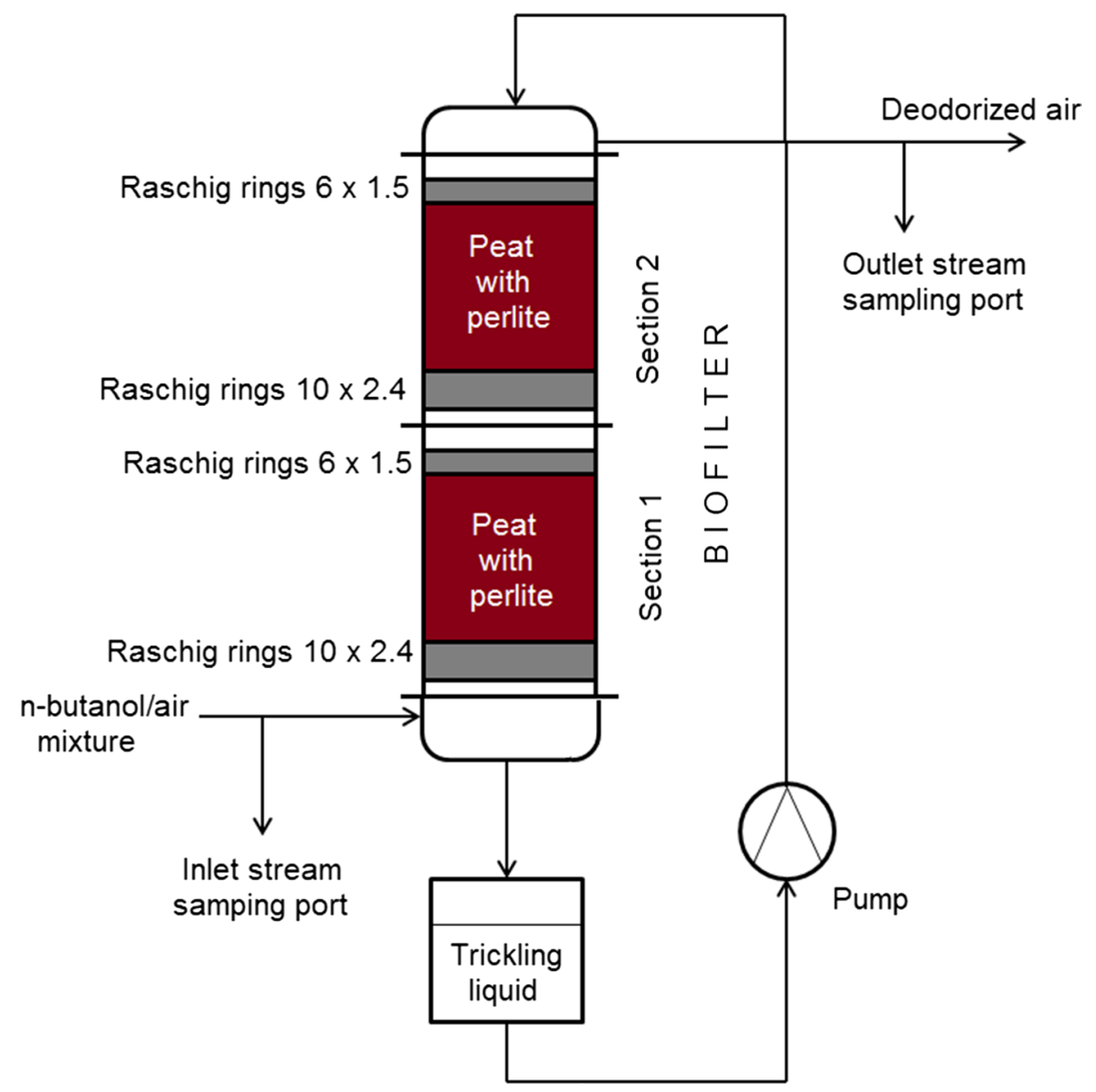

biofiltration of air polluted with $n$-butanol vapors [16]. Thus, the experimental comparison between the process efficiency (conventional biofiltration versus biotrickling filtration) is interesting both from scientific as well as practical points of view. These results indicate that $n$-butanol biofiltration precedes with much higher efficiency in biotrickling filters (95-99\%), keeping high removal efficiency even for increased inlet loads, as compared to conventional biofiltration (80-90\%).

\section{Experimental}

The research was carried out in a two-section biotrickling filter, shown schematically in Fig. 5. The biofilter was made of organic glass and packed with a commercially available mixture of peat and perlite (COMPO SANA, Compo, Germany). Dimensions and process parameters of a biofilter are given in Table 1.

After placing a filter packing bed in the individual sections and having the bioreactor twisted, a flow of a clean air as well as a trickling of a liquid were introduced through a packed bed. The intensity of air and trickling liquid flows are shown in Table 1. The activation of the biofilter packing lasted 4 days, and as a trickling liquid a buffered peptone water medium was used. After activation of the bed, the flow of $n$-butanol and air mixture was started, further using a trickling liquid as described above. After 4 days of operation of the system, the liquid used was replaced with a fresh medium. The composition of the medium was changed and it is as follows: $\mathrm{Na}_{2} \mathrm{HPO}_{4} \cdot 2 \mathrm{H}_{2} \mathrm{O}\left(15.2 \mathrm{~g} \mathrm{dm}^{-3}\right), \mathrm{KH}_{2} \mathrm{PO}_{4}$ $\left(3 \mathrm{~g} \mathrm{dm}^{-3}\right), \mathrm{NaCl}\left(0.5 \mathrm{~g} \mathrm{dm}^{-3}\right)$, and $\mathrm{NH}_{4} \mathrm{Cl}\left(1 \mathrm{~g} \mathrm{dm}^{-3}\right)$. A trickling liquid of such a composition was changed every 4 days. During the tests, at least once a day, gas samples were taken from the inlet and outlet streams. The flow of the gas mixture stream at the inlet to the biofilter and the pressure drop on the filter bed were regularly controlled. The temperature of the filter bed was in the range $23-25^{\circ} \mathrm{C}$.

Odour intensity of the air samples was determined using an electronic nose and artificial neural network. Electronic nose analyses were carried out using an e-nose prototype equipped with eight chemical gas sensors: ION Science MiniPID, Figaro FECS44-100, Figaro FECS50-100, Figaro TGS2600, Figaro TGS2602, Figaro TGS2603, Figaro TGS823, Figaro TGS8100. The sensor characteristics are presented in Table 2 . The collected samples were sucked 
Table 2 Electronic nose sensors characteristics

\begin{tabular}{lll}
\hline Sensor model & Sensor type & Detected compounds \\
\hline ION Science MiniPID & Photoionisation & Aromatic hydrocarbons, isobutylene \\
Figaro FECS44-100 & Electrochemical & Ammonia, amines \\
Figaro FECS50-100 & Electrochemical & Hydrogen sulfide, mercaptanes \\
Figaro TGS2600 & Metal oxide semiconductor & Ethanol, isobutane \\
Figaro TGS2602 & Metal oxide semiconductor & Hydrogen sulfide, toluene, ammonia \\
Figaro TGS2603 & Metal oxide semiconductor & Trimethylamine, methyl mercaptane, ethanol \\
Figaro TGS823 & Metal oxide semiconductor & Benzene, $n$-hexane, acetone \\
Figaro TGS8100 & Metal oxide semiconductor & Methane, isobutene, ethanol \\
\hline
\end{tabular}

Fig. 6 Architecture of the artificial neural network

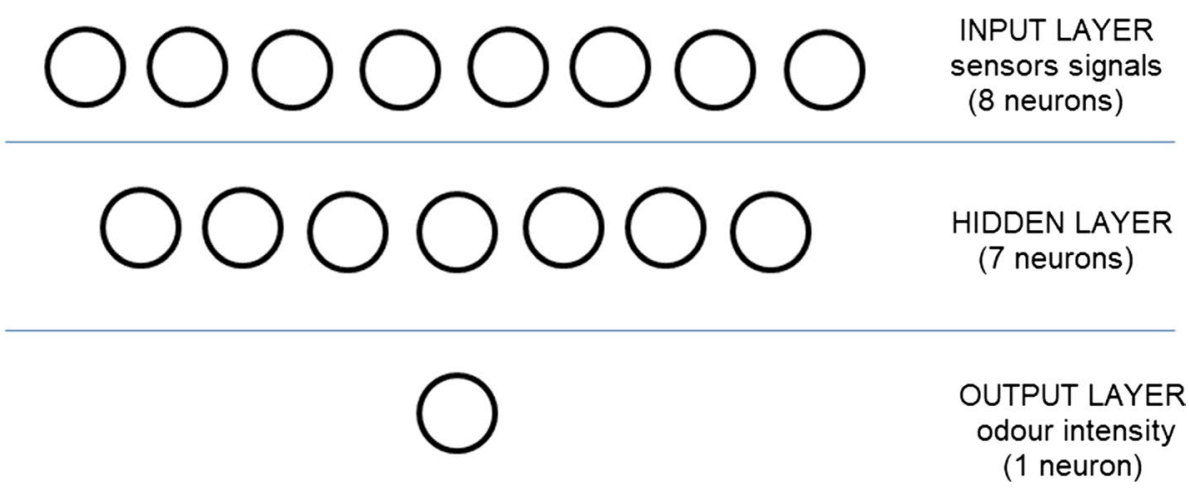

\begin{tabular}{ll}
\hline $\begin{array}{l}\text { Intensity } \\
\text { level }\end{array}$ & Odour strength \\
\hline 0 & No odour \\
1 & Very weak \\
2 & Weak \\
3 & Distinct \\
4 & Strong \\
5 & Very strong \\
6 & Extremely strong \\
\hline
\end{tabular}

The weights were modified until the error between the

Table 3 VDI 3940 Odour intensity scale

by a membrane pump into the e-nose chamber for $15 \mathrm{~s}$. The sample was then kept in the chamber for $30 \mathrm{~s}$. The purified air was then directed into the chamber for regeneration of the sensors. For data analysis, the maximum signal value of each sensor was used.

The odour intensity of the sample was determined using previously designed Artificial Neural Network (topology: 8-7-1). Architecture of the network is presented in Fig. 6.

Three layer neural network was designed. The ANN learning process was based on the analysis of $n$-butanol samples of known odour intensity using electronic nose and sensory analysis. It was carried out by four persons, selected according to the procedure described in [22]. Each member of the panel was responsible for assigning the appropriate odour intensity value to a given sample using a seven-step scale described in German Standard VDI 3940 (Table 3). measured and predicted values are minimized. RStudio Desktop (v. 1.0.143) software was used as the computational software.

Concentrations of $n$-butanol in the gas samples at the inlet and outlet of the biofilter were determined using a VARIAN CP-3800 gas chromatograph with a flame ionization detector (FID). A $30 \mathrm{~m}$ long HP-5MS capillary column was used (inner diameter $0.25 \mathrm{~mm}$, film thickness $0.25 \mu \mathrm{m}$ ). Conditions of chromatographic analysis were as follows: carrier gas: nitrogen; carrier gas flow: $2 \mathrm{~cm}^{3} \mathrm{~min}^{-1}$; split: 3 ; oven temperature: $150{ }^{\circ} \mathrm{C}$; injector temperature: $150{ }^{\circ} \mathrm{C}$; FID temperature: $200{ }^{\circ} \mathrm{C}$; total time of a single analysis: $5 \mathrm{~min}$. The analyses were performed in triplicate and the results are presented for mean values.

Removal efficiency (RE) was calculated using change in $n$-butanol concentration and odour intensity between inlet and outlet stream using Eqs. (1) and (2), respectively:

$\mathrm{RE}_{\text {conc }}=\frac{C_{\text {inlet }}-C_{\text {outlet }}}{C_{\text {inlet }}} \times 100 \%$,

$\mathrm{RE}_{\mathrm{OI}}=\frac{\mathrm{OI}_{\text {inlet }}-\mathrm{OI}_{\text {outlet }}}{\mathrm{OI}_{\text {inlet }}} \times 100 \%$.

Acknowledgements The investigations were financially supported by the Grant no. UMO-2015/19/B/ST4/02722 from the National Science Centre (Poland). 
Open Access This article is distributed under the terms of the Creative Commons Attribution 4.0 International License (http://creativecommons.org/licenses/by/4.0/), which permits unrestricted use, distribution, and reproduction in any medium, provided you give appropriate credit to the original author(s) and the source, provide a link to the Creative Commons license, and indicate if changes were made.

\section{References}

1. Vikrant K, Kim K-H, Szulejko JE, Pandey SK, Singh RS, Giri BS, Brown RJC, Lee SH (2017) Asian J Atmos Environ 11:139

2. Mudliar S, Giri B, Padoley K, Satpute D, Dixit R, Bhatt P, Pandey R, Juwarkar A, Vaidya A (2010) J Environ Manage 91:1039

3. Qian H, Cheng Y, Yang C, Wu S, Zeng G, Xi J (2018) Environ Sci Pollut Res 25:30021

4. Barbusinski K, Kalemba K, Kasperczyk D, Urbaniec K, Kozik V (2017) J Clean Prod 152:223

5. McNevin D, Barford J (2000) Biochem Eng J 5:231

6. Lebrero R, Hernández L, Pérez R, Estrada JM, Muñoz R (2015) J Environ Manage 151:124

7. Rybarczyk P, Szulczyński B, Gębicki J, Hupka J (2019) Biochem Eng J 141:146

8. Schiavon M, Ragazzi M, Rada EC, Torretta V (2016) Crit Rev Biotechnol 36:1143

9. Lee S-H, Li C, Heber AJ, Zheng C (2010) Chem Eng J 158:79

10. Prabhat Kumar T, Anil Kumar M, Chandrajit B (2011) Res J Chem Sci 1:83
11. Morotti K, Ramirez AA, Jones JP, Heitz M (2011) Environ Technol 32:1967

12. Hernández M, Quijano G, Noz RM, Bordel S (2011) Chem Eng J 172:961

13. Schmidt T, Anderson W (2017) Environments 4:57

14. Chen Y, Wang X, He S, Zhu S, Shen S (2016) J Environ Manage 165:11

15. Szulczyński B, Gębicki J, Namieśnik J (2018) Chem Pap 72:527

16. Szulczyński B, Rybarczyk P, Gębicki J (2018) Monatsh Chem 149:1693

17. Rumelhart DE, Hinton GE, Williams RJ (1986) Nature 323:533

18. Cheng Y, He H, Yang C, Zeng G, Li X, Chen H, Yu G (2016) Biotechnol Adv 34:1091

19. Kibazohi O, Yun SI, Anderson WA (2004) World J Microbiol Biotechnol 20:337

20. Thormann MN, Rice AV (2007) Fungal Divers 24:241

21. Schmidt T, Anderson WA, Schmidt T, Anderson WA (2017) Environments 4:57

22. Gębicki J, Dymerski T, Rutkowski SZ (2014) Environ Prot Eng 40:103

Publisher's Note Springer Nature remains neutral with regard to jurisdictional claims in published maps and institutional affiliations. 